\title{
El rol del Ministerio Público Fiscal en materia de derecho de la seguridad social en la Republica Argentina ${ }^{1}$
}

Patricio Jorge Torti Cerquetti ${ }^{2}$

\section{RESUMO}

En la Argentina, hasta 1994, el Ministerio Público carecía de rango constitucional. Recién a partir de la reforma constitucional y la sanción de la Ley Orgánica del Ministerio Público (primero la ley 24.946 y luego la ley 27.148) se terminó de delimitar su misión y su rol en los diferentes tipos de proceso. En el presente artículo se hará referencia al Ministerio Público Fiscal en su intervención especial en el ámbito del Derecho de la Seguridad Social en Argentina.

Palavras-chave: Ministério Público Fiscal. Constitución Nacional. Derecho de la Seguridad Social.

\section{EL MINISTERIO PÚBLICO EN ARGENTINA}

La Constitución de la Nación Argentina sancionada en 1853 dispuso, al organizar el Poder Judicial Federal, que este sería ejercido por una Corte Suprema compuesta por nueve miembros y dos fiscales, y por tribunales establecidos por el Congreso.

Por otra parte, la reforma acaecida en el año 1860 eliminó el

1 Data de recebimento: 14/01/2019. Data de aceite: 10/05/2019.

2 Abogado. Secretario Federal de la Fiscalía Federal de Primera Instancia de la Seguridad Social No 1 , Ministerio Público Fiscal (Argentina). Especialista en Derecho Judicial (UCES). Diplomado en Seguridad Social (UCES). Especialista en Gestión de Recaudación de los Recursos de la Seguridad Social (CEDDET). Doctorando en Ciencias Jurídicas (UCA). Docente universitario de las materias Derecho Constitucional (UCES) y Derecho de la Seguridad Social (UNLZ). Director de la Revista Argentina de Derecho de la Seguridad Social (IJ Editores). Publicista. E-mail: ptorti@mpf.gov.ar 
número de miembros que debía tener la Corte Suprema de Justicia de la Nación; aquellos "dos procuradores fiscales" del art. 91 de la Constitución Argentina de 1853 desaparecieron a raíz de la modificación introducida por la Convención Nacional de Santa Fe de 1860.

A partir de ahí, la regulación de lo atinente al Ministerio Público se instrumentó en diversas leyes ${ }^{3}$, y también en el decreto-ley 1285/58.

Cuando en el año 1993 se procedió a sancionar la ley 24.309 que declaró la necesidad de reformar la Constitución Nacional, se incluyó, entre los temas autorizados para ser examinados por la Asamblea Constituyente, la consagración del Ministerio Público "como órgano extrapoder" mediante la "habilitación de un artículo a incorporarse en la Segunda Parte, en el nuevo capítulo"4.

El producto resultante de esta permisión fue el nuevo art. 120 de la Ley Fundamental, que dotó al Ministerio Público de "independencia", "autonomía funcional" y "autarquía financiera", asegurando a sus integrantes "inmunidades funcionales" e "intangibilidad de remuneraciones". Como misión, se le asignó la tarea de "promover la actuación de la justicia en defensa de la legalidad, de los intereses generales de la sociedad, en coordinación con las demás autoridades de la República" ${ }^{\prime \prime}$.

Tal normativa constitucionalizó al Ministerio Público como un órgano extrapoder ${ }^{6}$, regulado en una sección independiente a la del Poder Judicial, cuyos atributos permiten afirmar que se ha querido dejarlo fuera del ámbito del órgano jurisdiccional. En ese sentido, la

\footnotetext{
3 Entre ellas, las $\mathrm{N}^{\circ} 27,1893,3367,4162,4055,17.516,18.345,19539,20.521$.

4 Conf. Carnota, Walter F., "El enclave constitucional del personal del Ministerio Público", La Ley 1997C, 796, cita online AR/DOC/6678/2001.

5 Conf. Carnota, Walter F., op. cit.

6 En ese sentido opinan Bidart Campos Germán, "Tratado Elemental de Derecho Constitucional Argentino", t. VI "La Reforma Constitucional de 1994", Ediar, Bs. As., 1995, pág. 487; Sagües, Néstor Pedro, "Constitución de la Nación Argentina, Introducción", Ed. Astrea, Bs. As. 1995, pág. 28; Quiroga Lavié, H., "Constitución de la Nación Argentina Comentada", Zavalía Editor, Buenos Aires, 1996, pág. 692; Seisdedos, Felipe, "Algunas reflexiones acerca de la independencia del Ministerio Público", Idearium, Revista de la Facultad de Ciencias Jurídicas y Sociales de la Universidad de Mendoza, № 10/12, pág. 980; Masnatta, Héctor, "Régimen del Ministerio Público en la Nueva Constitución", La Ley, 1994-E-878, Ekmekdjian, Miguel A. "Tratado de Derecho Constitucional", t.V, Depalma, Bs. As., 1999, págs. 631 y ss., entre otros.
} 
Procuración del Tesoro de la Nación expuso que el Ministerio Público, como órgano extra-poder, no posee por ello menor importancia jerárquica que los otros tres poderes ${ }^{7}$.

De esta forma, en un único artículo, el 120, la Constitución diseñó un Ministerio Público bicéfalo, con atribuciones propias de defensa de la legalidad, ejercida en todo tipo de proceso judicial, que incluye la actuación en casos en que se cuestiona la constitucionalidad de leyes y decretos. También se le reconoció la defensa de los intereses generales de la sociedad y de los pobres, ausentes e incapaces, a través del Defensor General8.

Pero la eficacia del Ministerio Público, está directamente relacionada con su independencia funcional y las garantías que la hagan posible. En tal sentido se ha dicho que "La Constitución Nacional destaca asimismo - y lo hace de un modo muy categórico- que el Ministerio Público es un órgano "independiente" - de los poderes Ejecutivo, Legislativo y Judicial - "autónomo - en el ejercicio de las funciones que le encomienda expresamente, y con autarquía, pues está sujeto al control externo de la Auditoría General de la Nación, y obligado a cumplir - como cualquier órgano autárquico- las leyes de administración financiera del Estado en la ejecución del Presupuesto"'.

En el año 1998, el Congreso Nacional sancionó la Ley Orgánica del Ministerio Público10, que establecía que:

(...) es un órgano independiente, con autonomía funcional y autarquía financiera, que tiene por función promover la

7 Conf. Procuración del Tesoro, Expte. PT 2973/94 de agosto de 1994. En el caso se debía decidir ante quien debía prestar juramento de acatar la Constitución Nacional el Sr. Procurador General. Sobre ello, el Procurador del Tesoro se expidió en el sentido de que aquél debía jurar ante el presidente de la Nación en su carácter de Jefe de Estado.

8 Conf. Gelli, María A. "Constitución de la Nación Argentina, Comentada y concordada", t.II, La Ley, pág. 580.

9 Herrero, Luis R. "El Ministerio Público Fiscal en el fuero de la seguridad social a la luz de la reforma constitucional de 1994 -Representante del Estado o de los intereses de la sociedad - Fiscalizador de los jueces o parte en el proceso", Revista del Ministerio Público Fiscal, N 5, pág. 156.

10 Ley 24.946, Boletín Oficial del 23/03/98. Modificada parcialmente por la ley 25.909, Boletín Oficial del 28/09/04. 
actuación de la justicia en defensa de la legalidad y de los intereses generales de la sociedad. Ejerce sus funciones con unidad de actuación e independencia, en coordinación con las demás autoridades de la República, pero sin sujeción a instrucciones o directivas emanadas de órganos ajenos a su estructura ${ }^{11}$.

Esta concepción se completó mediante la sanción de la Ley Orgánica del Ministerio Público Fiscal ${ }^{12}$ que agregó, a lo dispuesto por la normativa anterior ${ }^{13}$, que "En especial, tiene por misión velar por la efectiva vigencia de la Constitución Nacional y los instrumentos internacionales de derechos humanos en los que la República sea parte y procurar el acceso a la justicia de todos los habitantes"14, estableciendo sus funciones ${ }^{15}$.

Resulta interesante en esta oportunidad destacar el contenido del Capítulo 6 de la ley 27.148, referido a la "Actuación en materia no penal" delimitada en los artículos 30 y 31 de la Ley de referencia.

Cabe mencionar que el art. 31 de la referida Ley Orgánica estipula que:

La actuación del Ministerio Público Fiscal de la Nación en materia Civil, Comercial, Civil y Comercial Federal, Contencioso Administrativo Federal, Laboral, Seguridad Social y de Relaciones de Consumo de la Ciudad Autónoma de Buenos Aires estará a cargo de los fiscales y fiscales generales con competencia en esos asuntos.

Asimismo, equipara a estos magistrados y a los titulares de las unidades fiscales en materia no penal con asiento en las provincias ${ }^{16}$. En base a lo expuesto, se puede decir que:

(...) el Ministerio Público Fiscal en la República Argentina interviene y peticiona en todo asunto en el que se verifiquen

11 Conf. art. 1 de la ley 24.946.

12 Ley 27.148, Boletín Oficial del 18/06/15.

13 Idem. Cit. $\mathrm{N}^{\circ} 8$.

14 Conf. art. 1 de la ley 27.148 .

15 Conf. art. 2 de la ley 27.148.

16 Conf. art. 30 de la Ley 27.148. 
conflictos en los que se encuentre afectado de una manera grave el acceso a la justicia, por la especial vulnerabilidad de alguna de las partes o por la notoria asimetría entre ellas, o cuando se afecte el orden público y/o leyes no disponibles para las partes o estén amenazados o vulnerados los derechos humanos, las garantías constitucionales o la observancia de la Constitución Nacional ${ }^{17}$.

La actividad principal ha de orientarse a la defensa de la legalidad y la tutela de los intereses generales de la sociedad. En defensa de la legalidad significa que el Ministerio Público debe velar por el cumplimiento de la ley, no solo de parte de las personas, sino también por los propios poderes y órganos del Estado, en especial debe velar por la legalidad constitucional, ello debe entenderse como el control del cumplimiento de los derechos y garantías constitucionales; es un abogado de la constitución, un custodio de la legalidad constitucional. Es la conocida defensa del orden público ${ }^{18}$.

El nuevo cometido constitucional de defender los intereses generales de la sociedad en el proceso judicial, ha mutado el concepto y la función tradicional del Ministerio Público. Por esta razón, no sería desatinado afirmar que es un genuino representante del pueblo, aunque no sea elegido en forma directa. Asimismo, la defensa que ejerce en el proceso no se circunscribe solo a la legalidad o a los intereses generales de la sociedad, sino también a los derechos sociales ${ }^{19}$ y a los derechos de incidencia colectiva ${ }^{20}$.

La Constitución Nacional y la ley reglamentaria han individualizado ese interés público o social, cuya tutela se le ha encomendado al Ministerio Público, y comprende los siguientes tópicos: observancia de normas de orden público; representación de menores e incapaces; representación de ausentes y carentes de recursos económicos; acción judicial pública en materia penal y civil; declaración de insania;

17 Conf. arts. 2 inc. e. y 31 inc. B, Ley 27.148

18 Conf. Ortiz Pellegrini, Miguel A., "El Ministerio Público Fiscal en la Constitución Nacional", DJ 1997-2, 1067.

19 Arts. 14 bis y 33 de la Constitución Nacional Argentina.

20 Art. 43 de la Constitución Nacional Argentina. 
etc.; pureza del debido proceso; protección de bienes inmateriales vinculados al arte; a la naturaleza; a la historia; a los derechos humanos; etc.

También la Ley Suprema ha prescripto con señalado énfasis que el Ministerio Público es un órgano independiente de los Poderes Ejecutivo, Legislativo, y Judicial, pero esa cualidad comprende dos aspectos fundamentales: la autonomía funcional y la autarquía financiera.

La primera, se resuelve en la potestad de desempeñar la función requirente por sí, sin sujeción a instrucciones o sugerencias de otros órganos del Estado. En su exacto alcance esta cualidad, reconocida por la Constitución al Ministerio Público, encierra el poder, discrecional y exclusivo, de ejercer la función en la dirección y condiciones que establezca el propio órgano de control, sin intervención de ningún otro, con la única exigencia de adecuar su actividad a la ley. En la defensa de la ley y la tutela de los intereses sociales, es el titular del órgano, frente a cada caso concreto, el que debe establecer, sobre la base de la interpretación de las normas legales y constitucionales que libremente realice y de la valoración racional de los hechos y de las pruebas, la oportunidad y modos de actuación, sin que ninguna autoridad pueda sugerirle la conveniencia de actuar en modo distinto del que le dicta su conciencia.

Resulta necesario complementar la autonomía funcional con la autarquía financiera para redondear la garantía de la independencia del Ministerio Público. No hay dudas que la libertad de criterio para el ejercicio de la función requirente queda notablemente restringida por la falta de medios económicos o infraestructura material para ejecutar las decisiones adoptadas en ejercicio de esa libertad.

En coordinación con las demás autoridades de la República, se trata en primer lugar de una limitación a las funciones del Ministerio Público Fiscal, pues no puede actuar solitariamente al promover la actuación de la justicia en defensa de la legalidad y los intereses generales de la sociedad, sino en coordinación con las demás au- 
toridades de la Nación; debe concertar con ellas la búsqueda de un mismo fin, que es el fin del Estado, el bien común de la sociedad ${ }^{21}$.

\section{ACERCA DEL DERECHO DE LA SEGURDAD SOCIAL}

La vida del hombre está sometida a diversos acontecimientos y riesgos que, una vez producidos, generan una necesidad que debe ser atendida y satisfecha. Este esfuerzo de superación de la necesidad puede afrontarlo el hombre individualmente, o bien sumir la sociedad la tarea de repararla como una carga social que le incumbe colectivamente.

En los comienzos del desarrollo humano, el hombre estaba sujeto a su propia suerte $y$, por consiguiente, a él individualmente le incumbía proveerse de los elementos e instrumentos para satisfacer las necesidades más básicas. Con la evolución de la civilización y la vida en sociedad, muchas de las necesidades del hombre pasaron a ser satisfechas de manera compartida con los demás miembros del cuerpo social.

Más allá de la difusión que posee la expresión Seguridad Social, no es tan fácil delimitar con precisión cuál es su campo propio, ya que existen diferentes enfoques.

Como es sabido, el derecho a la seguridad social es un derecho humano:

Toda persona, como miembro de la sociedad, tiene derecho a la seguridad social, y a obtener, mediante el esfuerzo nacional y la cooperación internacional, habida cuenta de la organización y los recursos de cada Estado, la satisfacción de los derechos económicos, sociales y culturales, indispensables a su dignidad y al libre desarrollo de su personalidad ${ }^{22}$.

Conforme la Organización Internacional del Trabajo, la seguri-

21 Conf. Ortiz Pellegrini, Miguel A., op. cit.

22 Artículo 22 de la Declaración Universal de los Derechos Humanos. 
dad social es:

(...) la protección que la sociedad proporciona a sus miembros, mediante una serie de medidas públicas, contra las privaciones económicas y sociales que de no ser así ocasionarían la desaparición o una fuerte reducción de los ingresos por causa de enfermedad, maternidad, accidente de trabajo o enfermedad profesional, desempleo, invalidez, vejez y muerte, y también la protección en forma de asistencia médica y de ayuda a las familias con hijos ${ }^{23}$.

La Seguridad Social intenta asumir, el compromiso de garantizar a todos los miembros de la sociedad una plataforma de dignidad asentada en el principio de la solidaridad.

Entendida como como conjunto de recursos organizados por el Estado para satisfacer las necesidades de las personas que padecen consecuencias sociales, la seguridad social está estructurada en Argentina a partir de un Sistema Único de Seguridad Social ${ }^{24}$, creado por el decreto 2284/91 y compuesto por varios subsistemas: el Previsional $^{25}$, el de Asignaciones Familiares ${ }^{26}$, el de Desempleo ${ }^{27}$, el de Riesgos del Trabajo ${ }^{28}$ y el de Salud ${ }^{29}$.

\section{EL MINISTERIO PÚBLICO EN LA JUSTICIA DE LA SEGURIDAD SOCIAL}

En 1986 se sancionó la ley 23.473, que creó la Cámara Nacional de Apelaciones de la Seguridad Social cuyo artículo 5 dispuso la creación de dos fiscalías de Cámara, cuyos titulares ejercerán el ministerio público, reemplazándose mutuamente en caso de licencia, excusación, impedimento o vacante.

23 OIT- AISS 2001:9.

24 S.U.S.S.

25 Ley 26.425.

26 Ley 24.714.

27 Ley 24.013.

28 Ley 24.557.

29 Leyes 23.660 y 23.661 . 
Al crearse la Justicia Federal de Primera Instancia de la Seguridad Social ${ }^{30}$, se determinó la institución del "Ministerio Público de Primera Instancia que actuará ante los Juzgados Federales de Primera Instancia de la Seguridad Social de la Capital Federal"31.

El art. 6 de la ley 24.655, indica una lista de atribuciones y deberes a los fiscales generales, sin que deba excluirse la posibilidad de que dichos magistrados intervengan también en otras cuestiones que puedan estar comprendidas dentro de las previsiones del art. 120, $\mathrm{CN}$, y de la ley orgánica del Ministerio Público.

Cabe agregar que el Ministerio Público de la Seguridad Social extiende su actuación más allá de los tribunales del fuero especializado en la materia, pues también deben tomar la intervención que señalan las normas legales respectivas, los fiscales que actúan ante los juzgados federales con asiento en las provincias ${ }^{32}$.

Las leyes puntuales sobre la materia Seguridad Social ${ }^{33}$, imponen diligencias para promover la actuación judicial y participar a lo largo de todo el proceso en resguardo del orden público. Es decir que los fiscales no son ni pueden ser testigos prescindentes en tales procesos.

En el campo de los derechos sociales, económicos y culturales, los fiscales, siguiendo las directivas de la Procuración General de la Nacional, deben cumplir siempre con las funciones de requerir e investigar. Estos cometidos surgen de la obligación de promover la actuación ante el órgano jurisdiccional en defensa de la legalidad y los intereses generales de la sociedad. Esto implica una actitud proactiva. Se debe actuar de oficio si la situación lo amerita. La actitud pasiva es una negligencia y un incumplimiento al mandato constitucional y legal, además de una falta a la unidad de actuación que impone la Constitución Nacional y la Ley Orgánica del Ministerio Público.

Sobre el tema se ha dicho que la representación y la defensa de

30 Art. 1, ley 24.655, antes solo existía la Cámara Federal de la Seguridad Social, creada por ley 23.473. 31 Art. 5, ley 24.655 .

32 Art. 15, ley 24463, modificado por el art. 3, ley 24.655.

33 Las mencionadas leyes $23.473,24.463,24.655,24.946$ y 27.148 . 
los intereses públicos sociales que se implican o que pueden estar implicados en el proceso no estarían suficiente o completamente satisfechos si se los dejara librados a la actividad ciudadana particular, mediante el ejercicio de la llamada acción popular, o se los atribuyera exclusivamente al órgano del poder jurisdiccional del Estado. Entre ambos extremos, aparece un organismo del Estado encargado de una compleja serie de funciones, que no solamente representa los intereses patrimoniales del Estado, y los intereses individuales de determinada categoría de personas, sino que en todos los casos, se le erige en defensor del sistema de legalidad dentro del Estado de Derecho ${ }^{34}$.

El Ministerio Público ha de emplazar en el proceso judicial como una parte más y como titular excluyente de una pretensión procesal distinta a la del actor y demandado, cuyo fundamento o título lo constituye - por mandato constitucional - la defensa de la legalidad y los intereses generales de la sociedad.

A fin de velar por esta garantía constitucional, el Ministerio Público Fiscal está obligado a impugnar toda norma, acto o conducta procesal que menoscabe la imparcialidad del juez, quebrante la igualdad de las partes, niegue a estas la oportunidad de participar con utilidad en el proceso, tomar conocimiento de su actos y etapas, ofrecer y producir pruebas, gozar de audiencia, etc. En síntesis, debe atacar todo acto que impida desplegar en plenitud el derecho de defensa en juicio.

En esa línea, la Corte Suprema de Justicia de la Nación se pronunció sosteniendo que:

(...) cuando el Ministerio Fiscal es llamado a intervenir en una causa... el representante del Ministerio Público goza para la determinación de los alcances y modalidades del dictamen requerido de una plena independencia funcional respecto del tribunal ante el que actúa, que es ínsita de la magistratura que aquél ejercita y que configura una condición insoslayable que es reconocida a dicho ministerio

34 Conf. Díaz Clemente A., "Instituciones de Derecho Procesal", T. II A, Abeledo Perrot, Bs. As., Año 1972, pág. 458. 
como presupuesto esencial para el adecuado cumplimiento de su misión de preservar el orden público y procurar la defensa del orden jurídico en su totalidad ${ }^{35}$.

\section{CONCLUSIÓN}

La seguridad social tiene por finalidad otorgar cobertura a todos aquellos que se encuentren afectados por una contingencia social, razón por la cual, el acceso a las prestaciones sociales reviste un especial interés para todos los miembros de la comunidad.

Todos los poderes del Estado deben contribuir desde su ámbito de actuación para garantizar el funcionamiento y la sustentabilidad financiera del Sistema, la protección de los ancianos, los niños, las mujeres embarazadas, las personas por nacer y todos los sectores vulnerables de la República así lo exigen.

A nivel mundial se aprecia una tendencia a favor de la ampliación del concepto y del contenido de la Seguridad Social, toda vez que el rol de la seguridad social ha cambiado de manera fundamental en los últimos años, pues va más allá de la redistribución de los ingresos y las prestaciones, para lograr un bienestar mínimo o asegurar el acceso a las necesidades esenciales.

Cabe recordar que la Constitución Nacional en su art. 120 y el art. $1^{\circ}$ de las Leyes 24.946 y 27.148 colocan en cabeza del Ministerio Público la función de promover la actuación de la justicia en defensa de la legalidad y los intereses generales de la sociedad. En consonancia con ello debe velar por el efectivo cumplimiento del debido proceso legal, representar y defender el interés público en todas las causas $\mathrm{y}$ asuntos que conforme a la ley se requiera, intervenir en todos los procesos judiciales en que se solicite la ciudadanía argentina, etc. ${ }^{36}$.

El Dr. Luis Herrero ${ }^{37}$ ha manifestado en una reciente publicación:

35 Conf. CSJN, Fallos: 315:2255.

36 Conf. art. 25 ley 24.946 y art. 31 ley 27.148 .

37 Camarista integrante de la Sala II de la Cámara Federal de la Seguridad Social en Argentina. 
“Dudo que exista en nuestro país una institución pública más ajustada a los principios republicanos y al Estado Social de derecho que el Ministerio Público Fiscal, a la luz de la actual normativa constitucional y reglamentaria que disciplina su trascendental cometido en el proceso judicial" ${ }^{\prime 3}$.

Luego de lo expuesto en materia de doctrina y las referencias normativas mencionadas sobre el Ministerio Público Fiscal, esta magistratura, muchas veces descuidada y apenas conocida en su proyección constitucional, tiene ahora un estatuto legal acorde con la alta misión que le concierne en la custodia del orden jurídico con base en la Constitución, la defensa de la causa pública y la tutela de los intereses generales de la sociedad ${ }^{39}$.

En definitiva, el Ministerio Público Fiscal en materia de derecho de la seguridad, desde el más alto sitial de lo jurídico, brega por el establecimiento de lo justo concreto, presupuesto ineludible para el logro de una paz social genuina y perdurable, ejerciendo las funciones que le son propias y desplegando todos los esfuerzos necesarios para que así sea.

38 Conf. Herrero Luis R., "El Ministerio Público Fiscal en el Fuero de la Seguridad Social a la luz de la Reforma Constitucional de 1994. ¿Representante de del Estado o de los intereses generales de la sociedad? ¿Vigía de los jueces o una parte más en el proceso? Revista Aequitas, IJ-LXX-800, 01-12-2012, pág. 106. 39 Conf. Monti, José L., "El Ministerio Público a la altura de nuestro tiempo", ADLA 1998-A, 101. 


\section{THE ROLE OF THE PUBLIC PROSECUTOR'S OFFICE IN THE FIELD OF SOCIAL SECURITY LAW IN THE ARGENTINE REPUBLIC}

\section{ABSTRACT}

In Argentina, until 1994, the Public Ministry lacked constitutional status. Only after the constitutional reform and the enactment of the Organic Law of the Public Prosecutor's Office (first the law 24,946 and then the law 27,148) was finished delimiting its mission and its role in the different types of process. In this article, reference will be made to the Public Prosecutor's Office in its special intervention in the field of Social Security Law in Argentina.

Keywords: Public Prosecutor's Office. Constitution. Social Security Law.

\section{REFERÊNCIAS}

BIDART CAMPOS, Germán. Tratado Elemental de Derecho Constitucional Argentino, t. VI La Reforma Constitucional de 1994. Ediar, Bs. As., 1995. CARNOTA, Walter F. El enclave constitucional del personal del Ministerio Público, La Ley 1997-C, 796, cita online AR/DOC/6678/2001. Acesso em: 14 jan. 2019.

DÍAZ CLEMENTE A. Instituciones de Derecho Procesal, T. II A, Abeledo Perrot. Bs. As. 1972.

EKMEKDJIAN, Miguel Angel. Tratado de Derecho Constitucional. t.V, Depalma, Bs. As., 1999.

GELLI, María A. Constitución de la Nación Argentina, Comentada y concordada. t.II, La Ley.

GERMÁN, Bidart Campos. Tratado Elemental de Derecho Constitucional Argentino, t. VI La Reforma Constitucional de 1994., Ediar, Bs. As., 1995. HERRERO, Luis R. El Ministerio Público Fiscal en el fuero de la seguridad social 
a la luz de la reforma constitucional de 1994 - Representante del Estado o de los intereses de la sociedad - Fiscalizador de los jueces o parte en el proceso, Revista del Ministerio Público Fiscal, $N^{\circ} 5$.

HERRERO, Luis R. El Ministerio Público Fiscal en el Fuero de la Seguridad Social a la luz de la Reforma Constitucional de 1994. ¿Representante de del Estado o de los intereses generales de la sociedad? ¿Vigía de los jueces o una parte más en el proceso? Revista Aequitas, IJ-LXX-800, 2012.

MASNATTA, Héctor. Régimen del Ministerio Público en la Nueva Constitución, La Ley. 1994-E-878.

QUIROGA LAVIÉ, Humberto. Constitución de la Nación Argentina Comentada. Zavalía Editor, Buenos Aires, 1996.

SAGÜES, Néstor Pedro. Constitución de la Nación Argentina, Introducción. Ed. Astrea, Bs. As. 1995.

SEISDEDOS, Felipe. Algunas reflexiones acerca de la independencia del Ministerio Público, Idearium. Revista de la Facultad de Ciencias Jurídicas y Sociales de la Universidad de Mendoza, $N^{\circ} 10 / 12$. 



\section{VENDA PROIBIDA IMPRESSO COM RECURSOS PÚBLICOS}


Rua Assunção 1.200 - José Bonifácio, Fortaleza-CE

CEP: 60.050-011 - Fone: (85) 3452.4521 / 3433.7713 www.mpce.mp.br/institucional/esmp





